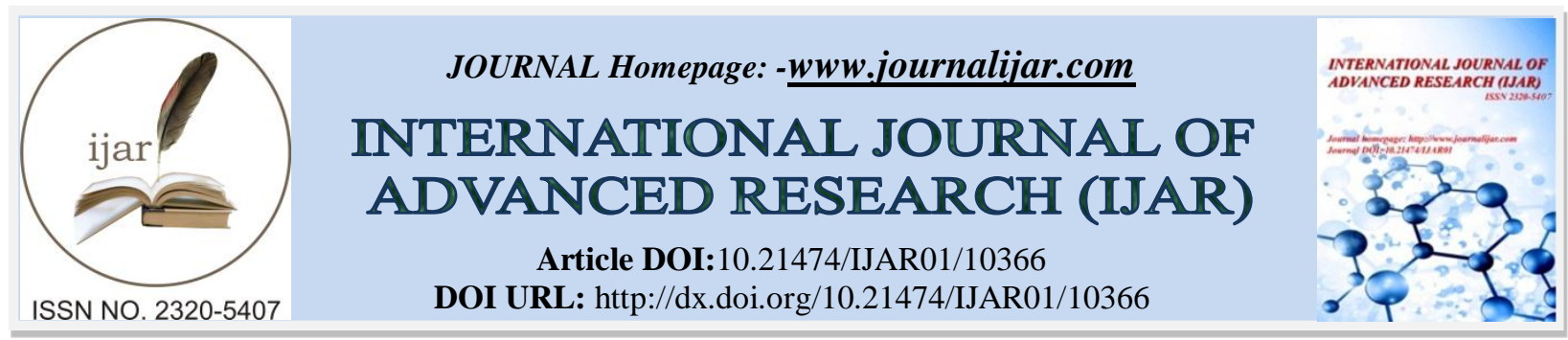

RESEARCH ARTICLE

\title{
MEASURING VOLATILITY USING GARCH MODELS : AN APPLICATION TO SELECTED STOCK OF DHAKA STOCK EXCHANGE
}

\author{
Sharmin Islam ${ }^{1}$, Dr. Rehena Parveen ${ }^{1}$, Sabrina Rahaman ${ }^{1}$ and Mabia Khatun ${ }^{2}$ \\ 1. Dept. of Statistics, Faculty of Science, Bangabandhu Sheikh Mujibur Rahman Science and Technology \\ University, Gopalganj-8100, Bangladesh. \\ 2. Dept. of Finance and Banking, Faculty of Business Studies, Bangabandhu Sheikh Mujibur Rahman Science and \\ Technology University, Gopalganj-8100, Bangladesh.
}

\section{Manuscript Info}

Manuscript History

Received: 30 November 2019

Final Accepted: 31 December 2019

Published: January 2020

Key words:-

Stock Market Volatility, Return Series, GARCH Modeling

\begin{abstract}
Stock market is an important part of economy of a country. Measuring stock market volatility is an vital issue in finance. There are various models to evaluate volatility. The daily return series shows that there is a variation of closing prices of $\mathrm{AB}$ bank. The data of $\mathrm{AB}$ bank includes daily closing prices from 01-01-2015 to 05-10-2017 from Dhaka Stock Exchange (DSE) library to forecast phenomena of stock market volatility. We use GARCH models to assess the volatility of stocks from banking sector and find that GARCH $(1,1)$ model is best for measuring volatility of the stocks of $\mathrm{AB}$ bank. Once if we measure the volatility then it is possible to make best prediction when to buy and when to sell a stock.
\end{abstract}

Copy Right, IJAR, 2020,. All rights reserved.

\section{Introduction:-}

The examination on the instability or volatility of securities exchange is firmly connected to the danger of benefits. Moreover, volatility is the measurement of risk. Higher volatility leads to risker the security. As volatility of stock market give helpful information in estimating hazard, numerous models are applied in predicting financial exchange development.

Now a days there are new technologies available in stock market which can help new user for making decision about sale and purchase of share. Time series forecasting is used to forecast the future based on historical observations.

Financial asset prices are described by the wonder known as volatility clustering [5]. The so-called autoregressive conditional heteroscedasticity (ARCH) or generalized autoregressive conditional heteroscedasticity (GARCH) models can capture such volatility clustering.

\section{Literature review:}

Explore on stock market volatility is broadly used in financial time series. Volatility analysis of stock markets is essential for the stockholder in forecasting and managing market risks more accurately what is useful in pricing capital assets and economic securities. GARCH and ARCH models are applicable in catching the financial exchange instability. These studies cover different regions/ countries.

In developed countries as like United States, United Kingdom, Germany, and Japan focus on stock market include Claessen \& Mittnik (2008), Ou \& Wang (2011), Choo \& Lee (2011), and Mootamri (2011). These research applied 
different frequency data. Some developing countries like Malaysia, Singapore, India, Pakistan, Saudi, China, Egypt, Vietnam etc also done some investigation on stock market are Mishra (2010), Alshogeathri (2011), Abdalla (2012), Maqsood et al. (2017), Wong \& Kok (2005) and Liu et al. (2009), Hien (2008).

In assessing the presentation of models, past investigations apply distinctive evaluation measures. The most widely applied measures include Mean Square Error (MSE), Root Mean Square Error (RMSE), and Mean Absolute Percent Error (MAPE).

Liu et al. (2009), Alberga et al. (2008), and Hien (2008) reported that GARCH/ GARCH type models is the best model for forecasting stock market volatility. Liu et al. (2009) investigated the forecast of stock market volatility in China using GARCH model and discovered that volatility forecasts by the GARCH-SGED model are more accurate than those generated using the GARCH-N model.

Alberga et al. (2008) searched the predictable stock market volatility in Israel using GARCH model. They found that asymmetric GARCH model with fat-tailed densities improves overall estimation for measuring conditional variance and improve the forecasting performance.

\section{Methodology:- \\ Volatility Model:}

The Dhaka stock market is one of the least regulated market. In Asia, the stock exchanges are primarily arms of government, controlled by government appointees. The rapid climb in financial markets and therefore the continual development of latest and more complex financial instruments, there's an ever-growing need for theoretical and empirical knowledge of the volatility in financial time series. It is widely known that the daily returns of monetary assets, especially of stocks, are difficult, if not impossible, to predict, although the volatility of the returns seems to be relatively easier to forecast. Therefore, it is hardly surprising that financial volatility has played such a central role in modern pricing and risk management theories. Several indices are available for Dhaka. The data set we use is the DSE20 capital index, which covers 20 largest and most liquid stocks listed and quoted on the Dhaka Stock Market Exchange (DSE), weighted by the market capitalization without dividends reinvested. Although the method provides a more efficient volatility estimator in terms of approximating the diffusion term in a small sample, it is subject to more biases due to the closure of the stock market overnight [6].

\section{Daily Return Series Measurement:}

The daily returns calculated are the logarithmic (continuously compounded) returns, rather than the arithmetic returns, since they are considered symmetric whereas the arithmetic returns are not. Nevertheless, the difference between both types is large only when percent changes are high, as both are approximately equal for small returns.

The logarithmic daily returns are calculated according to the following: $R_{t}=\ln \left(\frac{P_{t}}{P_{t-1}}\right)$.

where, $P_{t}$ is the daily closing price index, and $P_{t-1}$ is the yesterday closing price index [7].

\section{Garch :}

For the ARCH(q) model, in most empirical studies, q has to be large. This motivates Bollerslev (1986) to use the $\operatorname{GARCH}(\mathrm{p}, \mathrm{q})$ specification which is defined as

$$
\begin{aligned}
& r_{t}=\mu+\sigma_{t} \varepsilon_{t} \\
& \sigma_{t}^{2}=\lambda+\alpha \sum_{t=1}^{N_{T+1}}\left(r_{t+h-1}-\mu\right)^{2}+\sum_{j=1}^{p} \beta_{j} \sigma_{t-j}{ }^{2}
\end{aligned}
$$

Again, the selection of $\mathrm{p}$ and $\mathrm{q}$ is an important empirical question. As in the ARCHmodel, BIC is used to choose $\mathrm{p}$ and $\mathrm{q}[13]$.

The conditional variance equation in $\operatorname{GARCH}(1,1)$ model process can be modeled as:

$$
\sigma_{\mathrm{t}}^{2}=\alpha_{0}+\alpha_{1} \varepsilon_{\mathrm{t}-1}^{2}+\beta_{1} \sigma_{\mathrm{t}-1}^{2} \text {, }
$$

$\varepsilon_{\mathrm{t}}$ is a discrete-time stochastic defined to be $\varepsilon_{\mathrm{t}}=\mathrm{z}_{\mathrm{t}} \sigma_{\mathrm{t}}$ given $\mathrm{z}_{\mathrm{t}} \sim$ iid $(0,1)$ and $\sigma_{\mathrm{t}}$ is the conditional standard deviation of return at time t. All paremeters $\alpha_{0}, \alpha_{1}$ and $\beta_{1}$ are non negative. The stationary condition of $\sigma+\beta<1$ 
should hold to ensure weakly stationary of GARCH process. $\alpha_{1}$ Indicates the short-run persistency of stocks while $\beta_{1}$ implies the long-run persistency.

\section{Model Evaluation:}

The selection of model is a vital segment of any statistical analysis and is a key to the realization of science. Many authors have examined many tools like R2, Adjusted R2, AIC, SIC, Mallows's Cp criterion and forecast Chi square test for selecting the best model. All these criteria aim at minimizing the residual sum of squares (RSS). Here except R2 all the criteria impose a penalty for including large number of regressor.[5]

\section{Akaike's Information Criteria (AIC) and Bayesian Information Criteria (BIC):}

In Model selection AIC (Akaike's Information Criteria) and BIC (Bayesian Information Criteria) are considered as the widely used criteria. The AIC can be defined as a measure of the goodness of fit of any estimated statistical model. AIC generally tries to find unknown model that has high dimensional reality. This means the models are not true models in AIC. [5][14]

$\mathrm{AIC}=\mathrm{e}^{2 \mathrm{k} / \mathrm{n}} \sum \frac{\mathrm{u}^{\wedge} 2 \mathrm{i}}{\mathrm{n}}=\mathrm{e}^{2 \mathrm{k} / \mathrm{n}} \frac{\mathrm{RSS}}{\mathrm{n}}$

where, $\mathrm{k}$ is the number of regressors (including the intercept) and $\mathrm{n}$ is the number of observations.

$\ln \mathrm{AIC}=\left(\frac{2 \mathrm{k}}{\mathrm{n}}\right)+\ln \left(\frac{\mathrm{RSS}}{\mathrm{n}}\right)$

Where, $\ln$ AIC $=$ natural $\log$ of AIC and $2 \mathrm{k} / \mathrm{n}=$ penalty factor. In comparing two or more models, the model with the lowest value of AIC is preferred. Akaike's Information Criteria is good for making asymptotically equivalent to cross-validation.

On the other hand, BIC is used for selecting model among a class of parametric models with different numbers of parameters. BIC is consistent and comes across only True models. Bayesian Information Criteria is good for consistent estimation.[14]

\section{Result and Discussion:-}

We analyze the data whether it is stationary or not, which is the initial and vital steps to determine the appropriate method by which we can fulfill the study.

\section{Time series plot of closing price of AB Bank:}

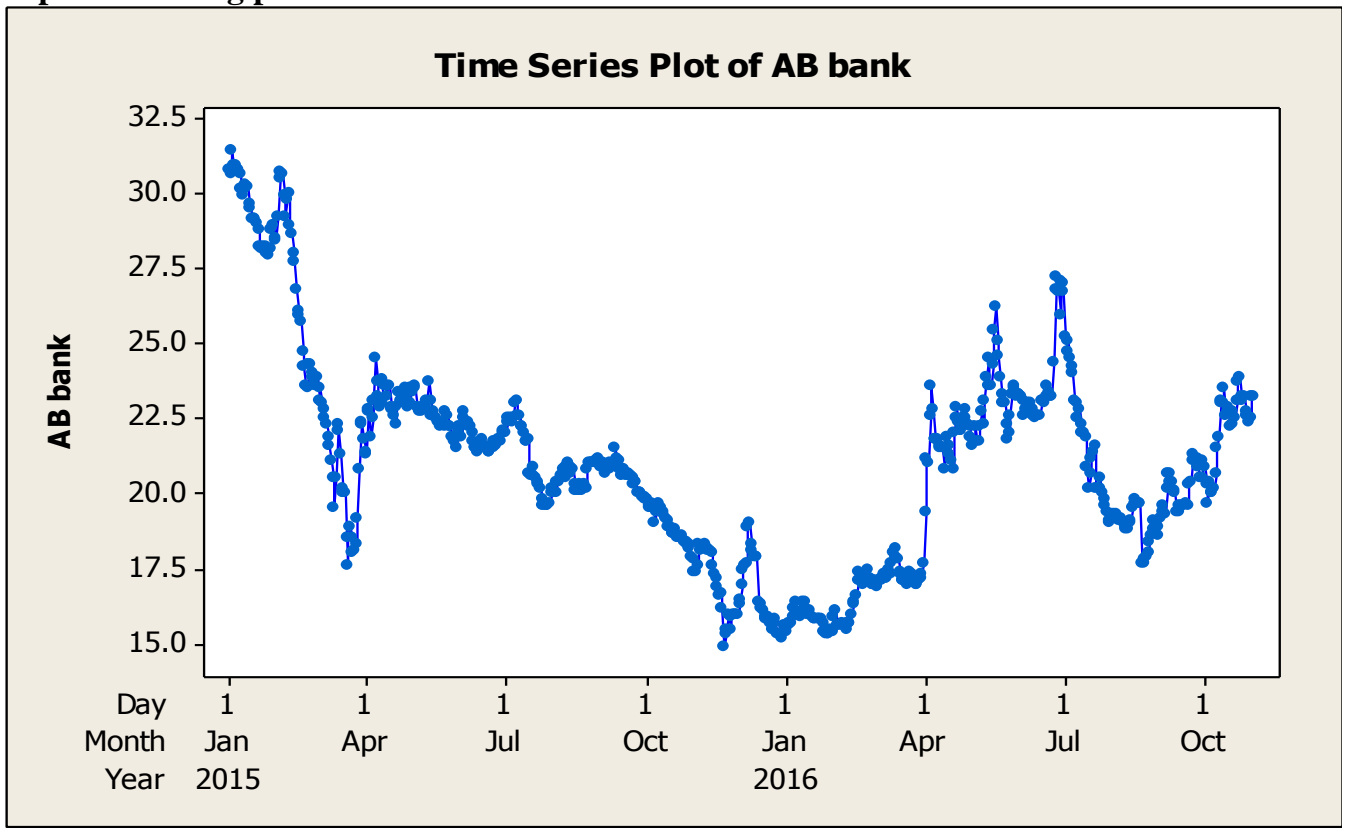

Fig. 1:- Time series plot of $A B$ bank. 
From the above time series plot, we see that over the period of study the time series data seems to be trending, suggesting perhaps that the mean and variance has been changing. So we can say that the daily data of closing price of AB bank of Dhaka Stock Exchange is not stationary. It is visual that mean and variance is not remains constraint from time to time, so we can say that the daily data of closing price is not stationary.

\section{$\mathrm{ACF}$ and PACF of closing price of $\mathrm{AB}$ bank:}
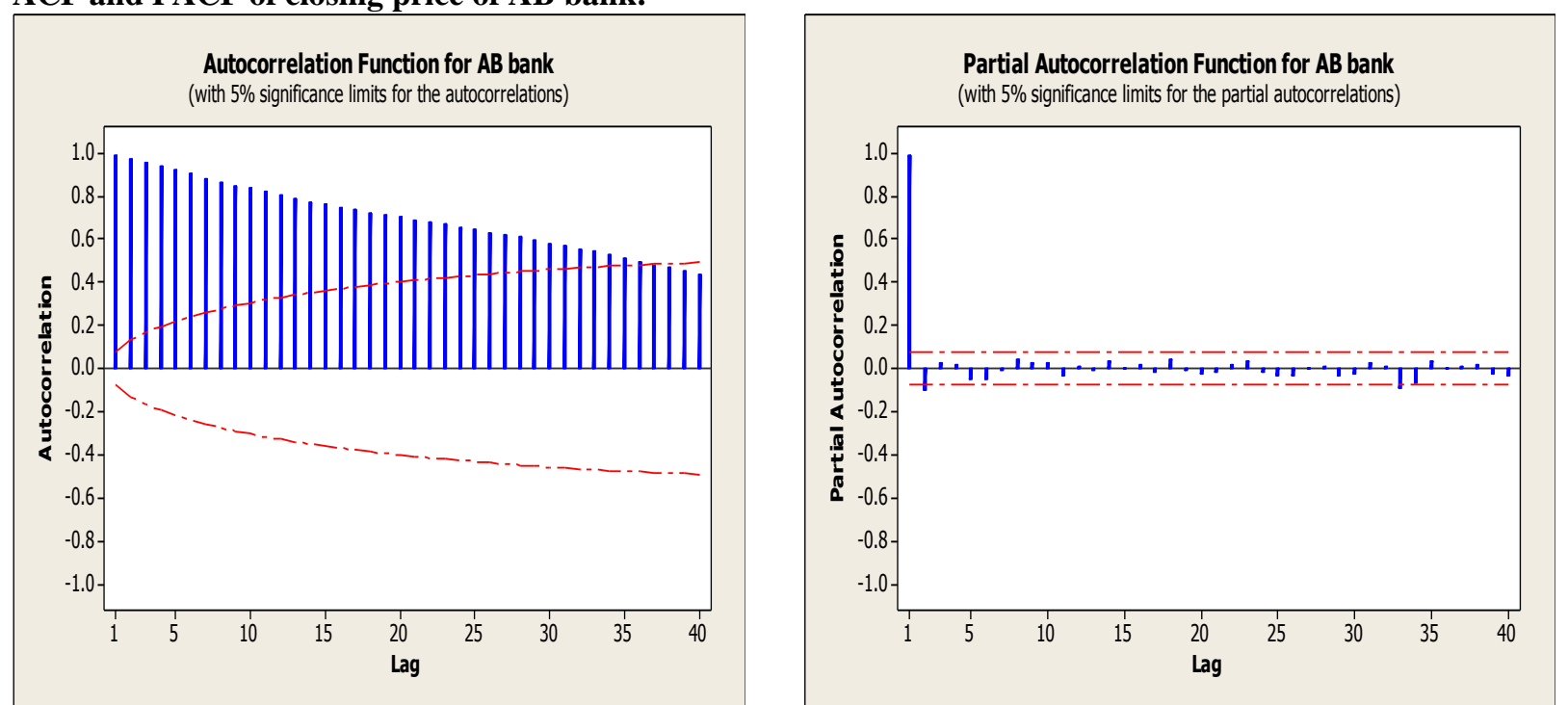

Fig. 2:- ACF and PACF of closing price of AB bank.

From the ACF and PACF of closing price series of selected companies of DSE are shown that autocorrelation coefficients at various lags are very high. The autocorrelation coefficients start at a very high value and declines very slowly towards zero. From the figure of selected companies of DSE, we observe that the autocorrelation coefficient starts at very high value at lag 1 and declines very slowly. There are single large spike of 1 and there are also insignificant spikes at different lag. Thus we conclude that the time series of closing price of selected companies of DSE are non-stationary.

\section{Daily return series of selected companies:}

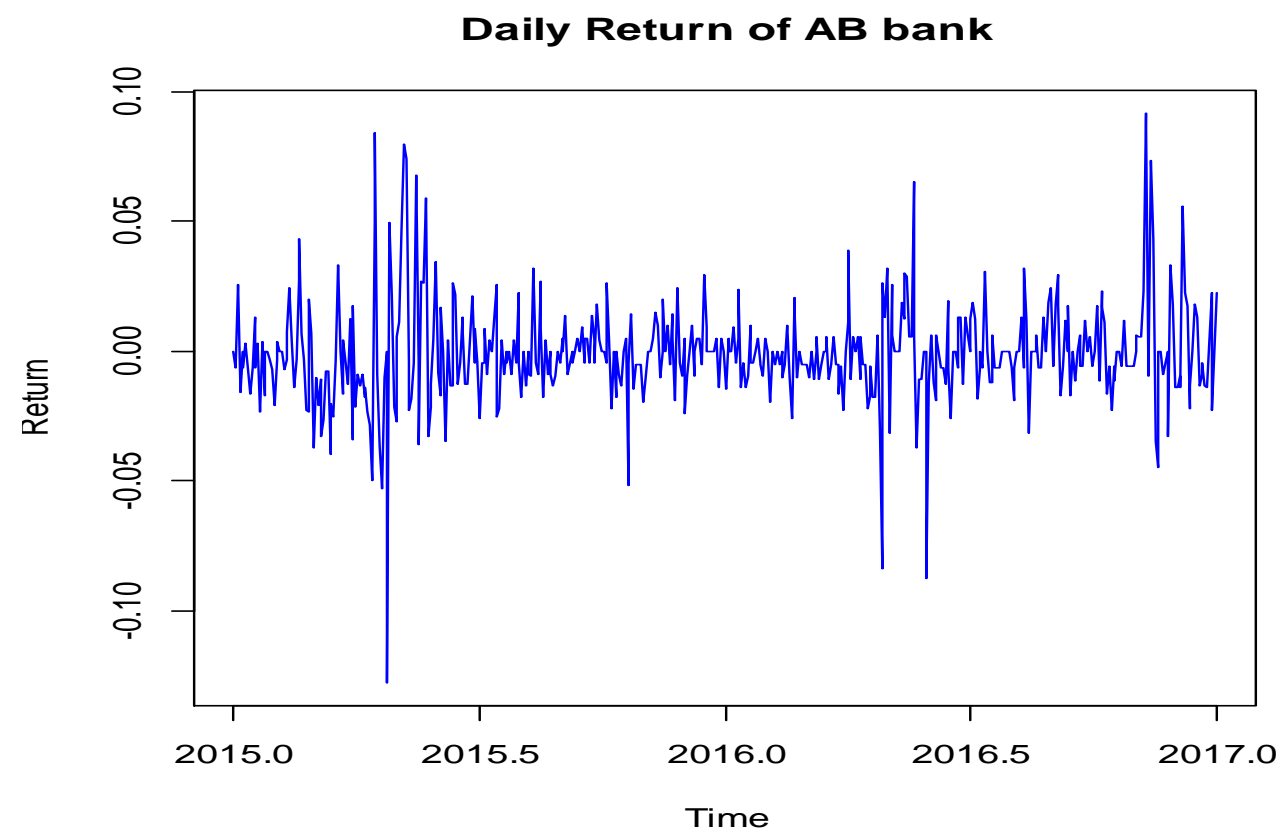

Fig. 3: Daily return series of $A B$ bank. 
The mean of the daily return series appears to be stable with an average return of approximately zero. Also the volatility or variability of the data changes over time. The daily return series of the selected bank shows that there is a small variation of closing price. There is no visual evidence of serial correlation in the return but there is evidence of serial correlation in the amplitude of the return.

Daily volatility of selected Bank:

\section{Daily Volatility of $A B$ bank}

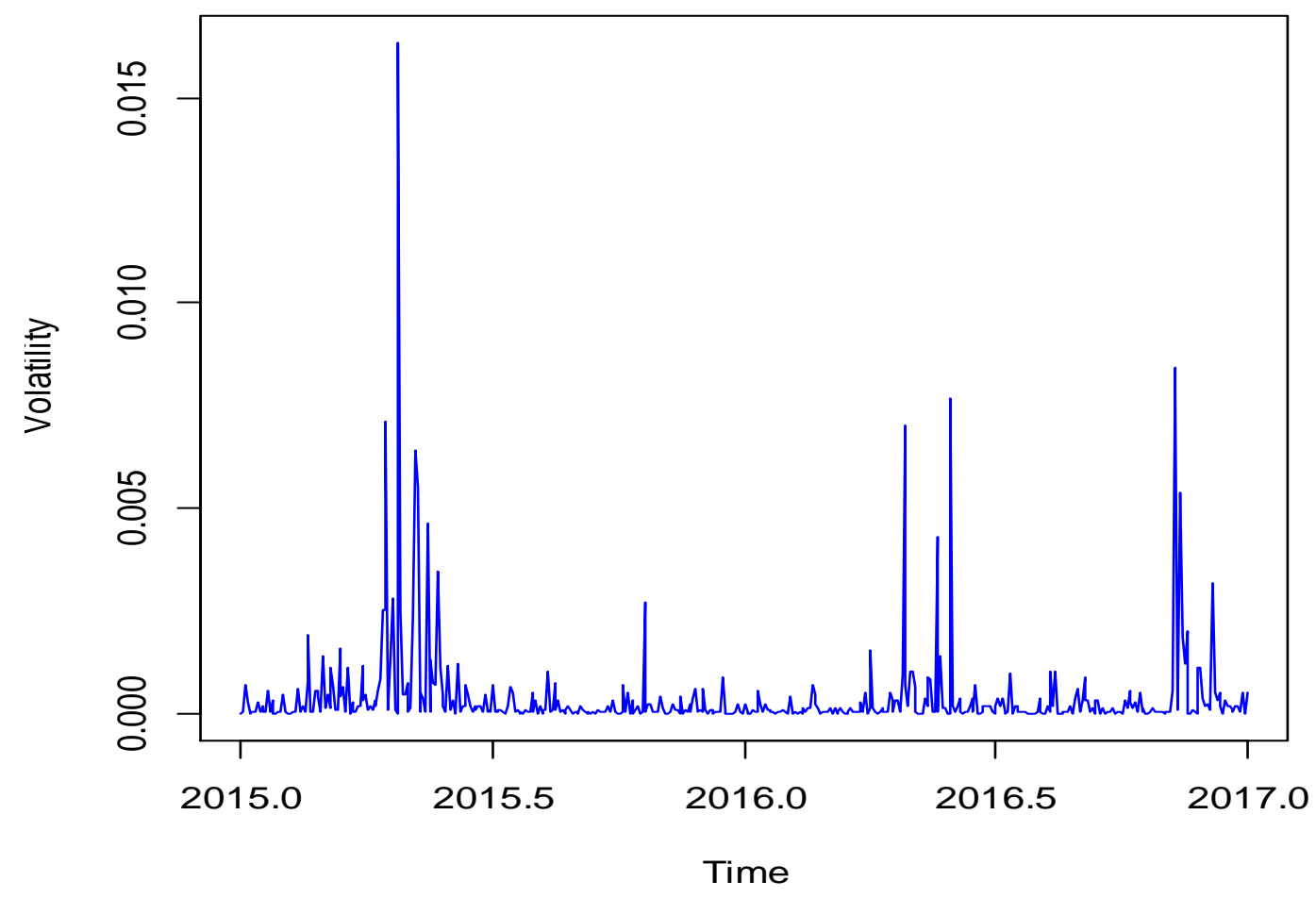

Fig. 4: Daily volatility of $A B$ bank.

From the above graphical plots of daily volatility series shows us several volatility periods for $\mathrm{AB}$ bank.

Application of different volatility models:

We consider different volatility models to estimate the parameters. Various deterministic volatility models are fitted to the data. Now the estimated result for the data set is give below:

Table. 1:- Estimation of GARCH model for AB bank.

\begin{tabular}{|l|l|l|}
\hline \multirow{2}{*}{ Model name } & \multicolumn{2}{|l|}{ Model selection criteria } \\
\cline { 2 - 3 } & AIC & BIC \\
\hline GARCH $(0,1)$ & -5.14862 & -5.12177 \\
\hline GARCH $(0,2)$ & -5.14644 & -5.11288 \\
\hline GARCH $(0,3)$ & -5.14372 & -5.10345 \\
\hline GARCH $(0,4)$ & -5.14093 & -5.09395 \\
\hline GARCH $(0,5)$ & -5.13799 & -5.0843 \\
\hline GARCH $(1,1)$ & -5.27592 & -5.24236 \\
\hline GARCH $(1,2)$ & -5.27404 & -5.23377 \\
\hline GARCH(1,3) & -5.27219 & -5.22521 \\
\hline GARCH $(1,4)$ & -5.27051 & -5.21682 \\
\hline GARCH(1,5) & -5.27007 & -5.20967 \\
\hline GARCH(1,0) & -5.20706 & -5.18021 \\
\hline GARCH $(2,1)$ & -5.27279 & -5.23252 \\
\hline
\end{tabular}




\begin{tabular}{|l|l|l|}
\hline GARCH( $(2,2)$ & -5.27106 & -5.22408 \\
\hline GARCH $(2,3)$ & -5.27139 & -5.2177 \\
\hline GARCH(2,4) & -5.26753 & -5.20713 \\
\hline GARCH $(2,5)$ & -5.26743 & -5.20031 \\
\hline GARCH $(3,1)$ & -5.26976 & -5.22278 \\
\hline GARCH(3,2) & -5.26811 & -5.21442 \\
\hline GARCH(3,3) & -5.26902 & -5.20862 \\
\hline GARCH(3,4) & -5.26456 & -5.19744 \\
\hline GARCH(3,5) & -5.26445 & -5.19063 \\
\hline GARCH(4,1) & -5.26734 & -5.21365 \\
\hline GARCH(4,2) & -5.26564 & -5.20523 \\
\hline GARCH(4,3) & -5.26374 & -5.19662 \\
\hline GARCH(4,4) & -5.26158 & -5.18775 \\
\hline GARCH(4,5) & -5.26149 & -5.18095 \\
\hline GARCH(3,0) & -5.24551 & -5.20524 \\
\hline GARCH(4,0) & -5.24464 & -5.19766 \\
\hline GARCH(5,0) & -5.24504 & -5.19134 \\
\hline GARCH(5,1) & -5.26415 & -5.20374 \\
\hline GARCH(5,2) & -5.26243 & -5.19532 \\
\hline GARCH(5,3) & -5.26327 & -5.18944 \\
\hline GARCH(5,4) & -5.66511 & -5.6047 \\
\hline GARCH(5,5) & -5.25851 & -5.17126 \\
\hline
\end{tabular}

In comparing the above GARCH model for $\mathrm{AB}$ bank, we can conclude that $\operatorname{GARCH}(1,1)$ model is more appropriate for daily return of closing price according to AIC and BIC.

\section{Conclusions and Final Remark:-}

We conduct the analyses to evaluate the forecasting performance of GARCH models to capture stock market volatility in Bangladesh. These models are evaluated using model selection criteria which are AIC and BIC. We test time series plot, correlogram test and get result from the graph that is time series is non-stationary. Then we also test the seasonality, we found that there is no presence of seasonality in the data. To make the series stationary we test unit root test and get stationary series and also from graphical presentation the daily return series of selected bank reveals that the volatility or variability of the data changes over time. Finally we found the best model that is $\operatorname{GARCH}(1,1)$ to measure the volatility of stock market.

\section{References:-}

1. Abdalla, S. Z. S., \& Suliman, Z. (2012). Modelling stock returns volatility: Empirical evidence from Saudi Stock Exchange. International Research Journal of Finance and Economics, 85, 166-179.

2. Alberg, D., Shalit, H., \& Yosef, R. (2008). Estimating stock market volatility using asymmetric GARCH models. Applied Financial Economics, 18(15), 1201-1208

3. Alshogeathri, M. A. M. (2011). Macroeconomic determinants of the stock market movements: empirical evidence from the Saudi stock market (Doctoral dissertation, Kansas State University).

4. Claessen, H., \& Mittnik, S. (2002). Forecasting stock market volatility and the informational efficiency of the DAX-index options market. The European Journal of Finance, 8(3), 302-321.

5. Gujarati, D.N (2014), Basic Econometrics, $5^{\text {th }}$ edition, McGraw-Hill Inc, New York.

6. Garman, M. B., \& Klass, M. J. (1980). On the estimation of security price volatilities from historical data. Journal of business, 67-78.

7. Haque, M. S., Eunus, R., \& Ahmed, M. (2001). Risk return \& market efficiency in capital market under distress: theory and evidence from DSE. Chittagong Stock Exchange Publication.

8. Hien, M. T. T., \& Thanh, T. (2008). Modelling and forecasting volatility by GARCH-type models: The case of Vietnam stock exchange. A Dissertation Presented in Part Consideration for the Degree of MA. Finance and Investment, 1-97.

9. Liu, H., Zhang, Z., \& Zhao, Q. (2009). The volatility of the index of shanghai stock market research based on ARCH and its extended forms. Discrete Dynamics in Nature and Society, 2009. 
10. Maqsood, A., Safdar, S., Shafi, R., \& Lelit, N. J. (2017). Modeling stock market volatility using GARCH models: A case study of Nairobi Securities Exchange (NSE). Open Journal of Statistics, 7(2), 369-381.

11. Ou, P., \& Wang, H. (2011, July). Modeling and forecasting stock market volatility by Gaussian processes based on GARCH, EGARCH and GJR models. In Proceedings of the World Congress on Engineering (Vol. 1, pp. 68).Link: http://iaeng.org/publication/WCE2011/WCE2011_pp338-342.pdf

12. Wei-Chong, C., See-Nie, L., \& Ung, S. N. (2011). Macroeconomics uncertainty and performance of GARCH models in forecasting Japan stock market volatility. International journal of business and social science, 2(1).

13. Yu, J. (2002). Forecasting volatility in the New Zealand stock market. Applied Financial Economics, 12(3), 193-202.

14. Difference between Similar Terms and Objects 2020, accessed 25 January 2020http://www.differencebetween.net/miscellaneous/difference-between-aic-and-bic/. 